\title{
Hepatic Microsomal Epoxidation of Bromobenzene to Phenols and Its Toxicological Implication
}

\author{
SERrine S. LaU ${ }^{1}$ and Vincent G. ZanNONI ${ }^{2}$ \\ Department of Pharmacology, University of Michigan Medical School, \\ Ann Arbor, Michigan 48109
}

Received January 8, 1979; accepted April 23, 1979

\begin{abstract}
Hepatic Microsomal Epoxidation of Bromobenzene to Phenols and Its Toxicological Implication. LAU, S. S. AND Zannoni, V. G. (1979). Toxicol. Appl. Pharmacol. 50, 309318. In vitro microsomal hepatic epoxidation of bromobenzene in rats and mice is presented in this study. Formation of $o$-bromophenol via bromobenzene-2,3-epoxide and $p$-bromophenol via bromobenzene-3,4-epoxide was assayed enzymatically and identified by a new, rapid and sensitive gas-liquid chromatography method using electron capture detection. Pretreatment of the animals with phenobarbital caused significant increases in both pathways whereas 3-methylcholanthrene or $\beta$-naphthoflavone caused a selective and marked increase of only the 2,3-epoxide pathway. Sodium dodecyl sulfate-gel electrophoresis of microsomal preparations resolved multiple forms of cytochrome $P-450$ and indicated that different forms of the heme protein were responsible for the formation of $o$-bromophenol and $p$-bromophenol. It is of interest that various inducers augment particular pathways for a common substrate especially since bromobenzene-3,4-epoxide and not the bromobenzene-2,3-epoxide has been proposed as the cytotoxic reactive metabolite of bromobenzene.
\end{abstract}

Treating rats or mice with ${ }^{14} \mathrm{C}$-labeled halogenated aromatic hydrocarbons such as bromobenzene has been used as a model to study the mechanism of centrolobular hepatic necrosis produced by this class of compounds (Davis et al., 1973; Krishna et al., 1971 ; Reid, 1972; Reid and Krishna, 1973; Reid, 1973; Reid et al., 1973; Sipes et al., 1971, 1974; Zampaglione et al., 1973). The development of hepatic necrosis produced by bromobenzene is presumably due to covalent binding of an active intermediate to liver macromolecules (Brodie et al., 1971; Jollow et al., 1974; Reid and Krishna, 1973). However, the precise mechanism leading to the pathological changes warrants further in-

\footnotetext{
1 Predoctoral candidate; partial fulfilment of the requirement for the degree of Doctor of Philosophy.

${ }^{2}$ To whom reprint requests should be sent.
}

vestigation (Gillette, 1974). Bromobenzene administered to rats is converted enzymatically to a chemically reactive metabolite, bromobenzene-3,4-epoxide, by the hepatic mixed function cytochrome $P-450$ oxygenase system (Brodie et al., 1971; Reid et al., 1971b). The epoxide may subsequently rearrange nonenzymatically to form $p$-bromophenol or may be converted to 3,4-dihydrodiol by epoxide hydrase. The dihydrodiol may be further dehydrogenated to 3,4bromocatechol (Jollow et al., 1974). Most of the 3,4-epoxide is converted $(70 \%)$ by glutathione transferase to a mercapturic acid (Brodie et al., 1971; Jollow et al., 1974; Zampaglione et al., 1973). In addition, induction with phenobarbital markedly increases the metabolism of bromobenzene via the 3,4-epoxide which resulted in the poten- 
tiation of hepatic necrosis, whereas, administration of SKF 525-A or piperonyl butoxide inhibited bromobenzene metabolism and prevented liver necrosis (Reid et al., 1971b). On the other hand, induction with 3-methylcholanthrene did not result in increased hepatic necrosis although the metabolism of bromobenzene was significantly enhanced (Reid et al., 1971a; Zampaglione et al., 1973). The major urinary metabolite was $o$-bromophenol and it has been postulated that its precursor bromobenzene-2,3-epoxide in not toxic (Zampaglione et al., 1973). The possibility should not be excluded that $o$-bromophenol may also form via an 1,2-epoxide intermediate.

The pathway for bromobenzene metabolism via its epoxide intermediate is shown below.

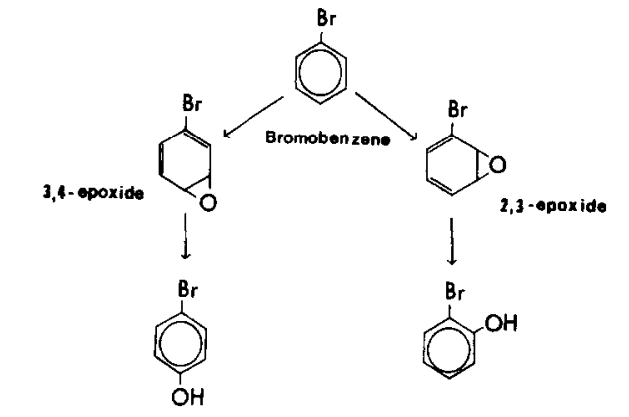

p-bromophenol

o.bromoohenol

FiG. 1. Bromobenzene metabolism.

The previous studies were in the main in vivo and further investigation was needed to determine the extent of the enzymatic conversion of bromobenzene via bromobenzene-2,3-epoxide to $o$-bromophenol.

\section{METHODS}

Chemicals and reagents. Bromobenzene, p-bromophenol, $\boldsymbol{o}$-bromophenol, $\boldsymbol{p}$-chlorophenol, $\boldsymbol{\beta}$-naphthoflavone, and 3,3',5,5'-tetramethylbenzidine were obtained from Aldrich Chemical Company, Milwaukee, Wisconsin. NADPH, Coomassie brilliant blue $\mathbf{R}$, and $N, N N^{\prime} N^{\prime}$-tetramethylenediamine were obtained from Sigma Chemical Company, St. Louis, Missouri. 3-Methylcholanthrene was obtained from Cali- biochem, San Diego, California. Acrylamide and pyridine were from J. T. Baker Chemical Company, Phillipsburg, New Jersey; sodium phenobarbital from Merck \& Company, Rahway, New Jersey. $N, N^{\prime}$-Methylene bisacrylamide from Eastman Kodak Company, Rochester, New York. Acetic anhydride and ethylether were obtained from Fisher Scientific Company, New Jersey. 3\% OV-17 Gas-Chrom Q (100/120 mesh) was obtained from Applied Science Laboratory, Inc. State College, Pennsylvania, sodium lauryl sulfate from Gallard-Schlesinger Chemical MFG. Corporation, Carle Place, New York.

Preparation of rat hepatic microsomes. Male Sprague-Dawley rats $(90-100 \mathrm{~g})$ were induced by pretreatment with phenobarbital once a day for 5 days $(50 \mathrm{mg} / \mathrm{kg})$, by ip injection in $0.2 \mathrm{ml}$ of $1.15 \% \mathrm{KCl}$ Tris buffer, $\mathrm{pH} \mathrm{7.4.} \mathrm{Other} \mathrm{groups} \mathrm{of} \mathrm{rats} \mathrm{received} \mathrm{ip}$ injections of 3-methylcholanthrene once a day for 5 days at a dose of $20 \mathrm{mg} / \mathrm{kg}$ in corn oil. $\beta$-Naphthoflavone suspended in corn oil was administered by ip injection to another group of rats at a dose of $40 \mathrm{mg} /$ $\mathrm{kg}$ once a day for 2 days followed by an increase to $60 \mathrm{mg} / \mathrm{kg}$ for 3 days. Control rats received corn oil once a day for 5 days. Animals were decapitated on day 6 and the livers were removed and immediately placed on ice and homogenized in 4 vol of $1.15 \%$ $\mathrm{KCl}$-Tris buffer, $\mathrm{pH}$ 7.4, with a Potter-Elvehjem glass homogenizer. The homogenates $(20 \% \mathrm{w} / \mathrm{v})$ were centrifuged at $15,000 \mathrm{~g}$ for $20 \mathrm{~min}$ and the postmitochondrial fraction was centrifuged at $100,000 \mathrm{~g}$ for $1 \mathrm{hr}$ to harvest the microsomes. The microsomes were made four times concentrated based on the initial homogenate volume in $1.15 \% \mathrm{KCl}$-Tris buffer, pH 7.4. Frozen microsomes maintain activity for at least 3 months if stored at $-20^{\circ} \mathrm{C}$. Microsomal protein was from 10 to $14 \mathrm{mg} / \mathrm{ml}$. Protein was determined by the method of Lowry et al. (1951) using bovine serum albumin as a standard.

Enzymatic assay of bromobenzene epoxidation. The following additions were made to control and experimental $10-\mathrm{ml}$ Erylenmeyer flasks. The flasks contained $0.1 \mathrm{M}$ sodium phosphate buffer, $\mathrm{pH} 7.4$, $0.1 \mathrm{ml}$ of microsomal suspensions $(1.0$ to $1.4 \mathrm{mg}$ protein), $3 \mu \mathrm{mol}$ of bromobenzene in $10 \mu \mathrm{l}$ of acetonitrile. The enzymatic reaction was started with the addition of $1 \mu \mathrm{mol}$ of NADPH in $0.1 \mathrm{M}$ sodium phosphate buffer, pH 7.4. NADPH was omitted from the control incubation fasks. Incubations were carried out for at least $10 \mathrm{~min}$ at $37^{\circ} \mathrm{C}$ in a Dubnoff metabolic shaking incubator at 80 oscillations/min; the total fluid volume of the incubation flask was $1.2 \mathrm{ml}$ made up to this volume with sodium phosphate buffer. The reaction rate was proportional to enzyme concentration and was linear with time to at least $6 \mathrm{~min}$. Acetonitrile $(10 \mu \mathrm{l})$ had no effect on the rate of oxidation of bromobenzene. One milliliter of the incubate was taken for product analysis at 2 and $5 \mathrm{~min}$. Product 
formation in duplicate incubations were in excellent agreement, from 1.0 to $1.5 \%$.

Identification of p-bromophenol and o-bromophenol. The products of bromobenzene metabolism, $p$-bromophenol formed via the 3,4-epoxide and o-bromophenol formed via the 2,3-epoxide, were extracted from the incubates and identified with gas chromatographic-electron capture detector analyses. Dihydrodiols formed enzymatically would be measured as phenols due to the subsequent deproteinization with $10 \mathrm{~N} \mathrm{H}_{2} \mathrm{SO}_{4}$. At various incubation times (2 and $5 \mathrm{~min}$ ), $20 \mu \mathrm{g}$ of $p$-chlorophenol in $20 \mu \mathrm{l} 95 \%$ ethanol was added as an internal standard to $1.0 \mathrm{ml}$ of incubate and the protein in the solution was precipitated with $0.5 \mathrm{ml}$ of $10 \mathrm{~N} \mathrm{H}_{2} \mathrm{SO}_{4}$ and placed in ice for $5 \mathrm{~min}$. The volume was supplemented with $0.5 \mathrm{ml}$ of distilled water. After $5 \mathrm{~min}$ in ice, the protein-free incubates were centrifuged at $3000 \mathrm{~g}$ for $15 \mathrm{~min}$. The acidified supernatant was removed and saturated with $\mathrm{NaCl}(0.8$ to $1.0 \mathrm{~g})$. Bromobenzene and its metabolites were extracted into $2.5 \mathrm{ml}$ of ethyl ether (certified spectroanalyzed). The phenols were back extracted into $2.0 \mathrm{ml}$ of $0.5 \mathrm{~N} \mathrm{NaOH}$; the basic extract was acidified with $0.5 \mathrm{ml}$ of $6 \mathrm{~N} \mathrm{H}_{2} \mathrm{SO}_{4}$ and saturated with $\mathrm{NaCl}$. Ether $(2.5 \mathrm{ml})$ was added and the metabolites were extracted and washed with $2.0 \mathrm{ml}$ of distilled water. All extractions were done by shaking the mixture at low speed in a shaker (100 oscillations/ $\mathrm{min}$ ) for $10 \mathrm{~min}$ and separation of aqueous and organic phases was carried out by centrifugation at $3000 \mathrm{~g}$ for $5 \mathrm{~min}$. The ether extracts were dried with $0.3 \mathrm{~g}$ of anhydrous $\mathrm{Na}_{2} \mathrm{SO}_{4}$. The dried ether extracts $(2.0 \mathrm{ml})$ were transferred to a $5-\mathrm{ml}$ conical glass tube. In order to prevent loss of phenols derivatization was carried out prior to evaporation. Twenty microliters of acetic anhydride, $20 \mu \mathrm{l}$ of pyridine (dried over $\mathrm{KOH}$ pellets), and $100 \mu \mathrm{l}$ of ethyl acetate were added for derivatization of the phenols. The tubes were capped, mixed, and heated at $75^{\circ} \mathrm{C}$ for $60 \mathrm{~min}$. This process removes all of the ether leaving the phenols in the ethyl acetate phase. The samples were cooled to room temperature and shaken for $1 \mathrm{~min}$ with $200 \mu \mathrm{l}$ of $0.5 \mathrm{~N} \mathrm{NaOH}$ to remove the excess reagents. After centrifugation $(3000 \mathrm{~g}$ for $10 \mathrm{~min})$, the aqueous fraction was removed via aspiration. The ethyl acetate phase was washed with $50 \mu \mathrm{l}$ of distilled water and $50 \mu 1$ of pentane to remove excess pyridine, mixed, and centrifuged. One to three microliters of the sample in the organic phase was subjected to gas chromatographic analysis. Under these conditions the recovery of phenols were $86 \%$.

Quantitative analysis of $p$-bromophenol and $o$-bromophenol was made on a Hewlett-Packard 7610A gas chromatograph equipped with an electron capture detector of ${ }^{63} \mathrm{Ni}$ (gc/ecd). The U-tube glass column sized $6 \mathrm{ft} \times 4 \mathrm{~mm}$ was packed with $3 \%$ OV-17 on 100/120 mesh on Gas-Chrom Q. Column temperature was $135^{\circ} \mathrm{C}$ isothermal; injector temperature was $150^{\circ} \mathrm{C}$. Argon: methane (95:5) gas was used as the carrier gas at a rate of $40 \mathrm{ml} / \mathrm{min}$; detector temperature was $200^{\circ} \mathrm{C}$; pulse interval was $50 \mu$ sec. The retention time of $p$-bromophenol was $3.8 \mathrm{~min}$; $o$-bromophenol, $3.1 \mathrm{~min}$; and p-chlorophenol, 2.1 min. Repeated injections were made at 10-min intervals.

Standard curves for $o$-bromophenol and $p$-bromophenol were obtained and plotted as the ratio of peak heights of $o$-bromophenol $/ p$-chlorophenol or $p$ bromophenol $/ p$-chlorophenol to varying amounts of $o$-bromophenol and $p$-bromophenol $(0.5$ to $3.0 \mu \mathrm{g})$. The products were previously added to microsomes, extracted, and derivatized. The ratio of peak height of $o$-bromophenol and $p$-bromophenol to $p$-chlorophenol provided a direct index of the amount of product formed from the enzymatic incubation of bromobenzene. To ensure against changes of column conditions and detector responses, standard curves were prepared with microsomes for each series of analyses. Further confirmation of the metabolites $p$ - and $o$-bromophenol was made by comparing the products of the enzymatic reaction with authentic samples by a Finnigan 3200 gas chromotographymass spectrometry analysis.

Sodium dodecyl sulfate-gel electrophoresis. Polyacrylamide slab gel electrophoresis was performed using the procedure based on the system of Laemmli (1970) and carried out using the modified method of Rikans et al. (1978). Microsomal samples (0.02 ml) containing $0.3-0.6 \mathrm{mg}$ protein $/ \mathrm{ml}$ previously treated with $1 \% \operatorname{SDS}$ and $1 \%$ mercaptoethanol at $100^{\circ} \mathrm{C}$ for 2 min were applied to $7.5 \%$ acrylamide gel and subjected to electrophoresis in a vertical slab assembly (Model SE 500, Hoefer Scientific Instruments, Inc.). Electrophoresis was carried out at $12.5 \mathrm{~mA} / \mathrm{gel}$ during stacking ( $1 \mathrm{hr}$ ) and at $25 \mathrm{~mA} / \mathrm{gel}$ during separation until the tracking dye was $1 \mathrm{~cm}$ from the bottom of the gel (approximately $2 \mathrm{hr}$ ). The gels were fixed in $\mathrm{H}_{2} \mathrm{O}$-2-propanol-acetic acid $(65: 25: 10)$ for $1 \mathrm{hr}$, stained in Coomassie blue in the same solvent for $1 \mathrm{hr}$, and destained at room temperature in $\mathrm{H}_{2} \mathrm{O}-$ 2-propanol-acetic acid $(80: 10: 10)$ until the background was cleared. The standard proteins used as molecular weight markers were $1.0 \mu \mathrm{g}$ of bovine serum albumin, 68,$000 ; 1.0 \mu \mathrm{g}$ of catalase, 56,000; 12.0 glucose-6-phosphate dehydrogenase, 51,000; and $7.0 \mu \mathrm{g}$ of horseradish peroxidase, 40,000 . For gels stained for heme with $3,3^{\prime}, 5,5^{\prime}$-tetramethylbenzidine$\mathrm{H}_{2} \mathrm{O}_{2}$, the electrophoresis procedure used was as described by Rikans et al. (1978). Microsomal samples $(0.1 \mathrm{ml})$ containing a protein concentration of $2-4 \mathrm{mg} / \mathrm{ml}$ were treated at room temperature with $1 \%$ SDS without mercaptoethanol. They were applied on a discontinuous gel which consisted of $7.5 \%$ acrylamide separating gel $(9 \times 15 \times 0.3 \mathrm{~cm})$ and 
a $3 \%$ acrylamide, photopolymerized stacking gel. Electrophoresis was at $25 \mathrm{~mA} /$ gel during stacking (1-1.5 hr) and $50 \mathrm{~mA} / \mathrm{gel}$ during separation (3-4 hr). The apparatus was kept in the dark throughout the electrophoresis. The gels were fixed for $1 \mathrm{hr}$ with methanol- $0.5 \mathrm{M}$ sodium acetate, $\mathrm{pH} 4.0(3: 7)$. The fixing solution was replaced with $250 \mathrm{ml}$ of freshly made $6.3 \mathrm{~mm} \mathrm{3,3}, 5,5^{\prime}$-tetramethylbenzidine in methanol- $0.25 \mathrm{M}$ sodium acetate $(\mathrm{pH} 4.0)(3: 7)$ and the gels remained immersed in the dark for $1 \mathrm{hr}$ prior to the addition of $\mathrm{H}_{2} \mathrm{O}_{2}$ at a final concentration of $30 \mathrm{~mm}$. The stain was developed for $24 \mathrm{hr}$.

Cytochrome P-450 determination in rat liver microsomes. Microsomal proteins $(1.5-2.0 \mathrm{mg})$ were suspended in $28 \%$ glycerol containing $0.05 \mathrm{M}$ sodium phosphate buffer and $1 \mathrm{mM}$ of EDTA in a total volume of $1.0 \mathrm{ml}$. Sodium dithionite $(1 \mathrm{mg})$ was used as the reducing agent added only to the experimental cuvette. Carbon monoxide was present in control and experimental cuvettes. The cytochrome $P-450$ content was determined from the reduced carbon monoxide difference spectrum according to the method of Omura and Sato (1974).

\section{RESULTS}

A hepatic microsomal enzymatic assay of bromobenzene oxidation and the detection of two of its metabolites, $o$-bromophenol and p-bromophenol, by a gas chromatograph with an electron capture detector ( $\mathrm{gc} / \mathrm{ecd}$ ) has been developed. The sensitivity of detection for both metabolites was determined by adding $o$-bromophenol and $p$-bromophenol to rat liver microsomes followed by extraction as described under Methods. Representative standard calibration curves are shown in Fig. 2. The curves are linear and represent a range from 0.5 to $3.0 \mu \mathrm{g}$ of added metabolites. Under the enzymatic assay conditions, the sensitivity of detection of $o$-bromophenol and $p$-bromophenol is $0.05 \mu \mathrm{g}$ per incubation flask. This represents $0.2 \mathrm{ng}$ of each product in a $1-\mu \mathrm{l}$ injection volume. One migrogram of p-bromophenol gives a ratio of peak height of 0.33 and a ratio of 0.75 for o-bromophenol. The mean of 10 standard curves for $p$-bromophenol gives a ratio of 0.31 for $p$-bromophenol and 0.8 for $o$-bromophenol. Standards consisting of $0.5,1.0,2.0$, and $3.0 \mu \mathrm{g}$ of each metabolite are run with each enzymatic incubation.

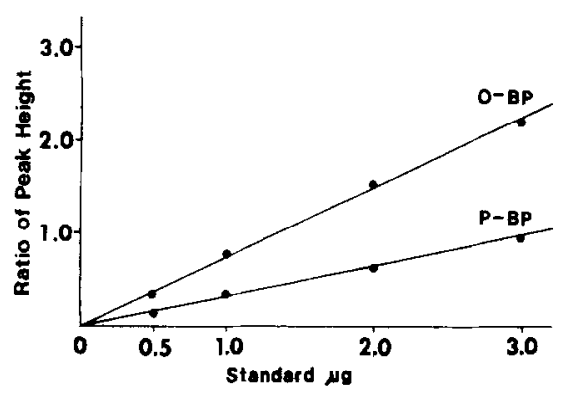

FIG. 2. Standard calibration curves for o-bromiophenol ( $o$-BP) and $p$-bromophenol ( $p$-BP). Standards $(0.5,1.0,2.0$, and $3.0 \mu \mathrm{g})$ with $20 \mu \mathrm{g}$ of $p$-chlorophenol as the internal standard were added to rat microsomes and extracted for GC/ECD analysis as described under Methods. Ratio of peak height $=$ standard internal standard.

The formation of $p$-bromophenol and $o$-bromophenol was proportional to enzyme concentration and the rate of the reaction was linear with time for at least $6 \mathrm{~min}$. Figures $3 \mathrm{~A}$ and $B$ illustrate the oxidation of bromobenzene via its 3,4-epoxide to $p$-bromo-

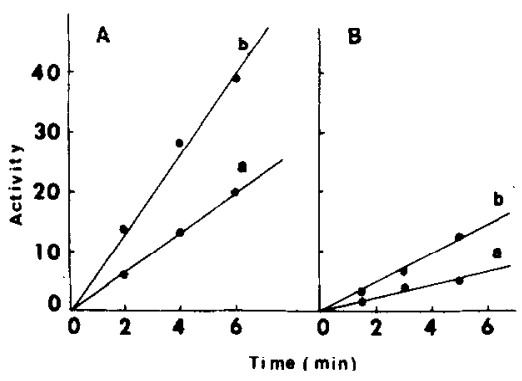

FIG. 3. Enzymatic oxidation of bromobenzene to $p$-bromophenol via 3,4-epoxidation. (A) a, Three micromoles of bromobenzene was incubated with $0.7 \mathrm{mg}$ of microsomes prepared from phenobarbitalpretreated rats. $b$, Three micromoles of bromobenzene was incubated with $1.4 \mathrm{mg}$ of microsomes prepared from phenobarbital-pretreated rats. The incubation conditions and inducer pretreatment were as described under Methods. Activity is expressed as nmol of product formed/time indicated. (B) a, Three micromoles of bromobenzene was incubated with $0.6 \mathrm{mg}$ of microsomes prepared from $\beta$-naphthoflavone-pretreated rats. b, Three micromoles of bromobenzene was incubated with $1.2 \mathrm{mg}$ of microsomes prepared from $\beta$-naphthoflavone-pretreated rats. The incubation conditions and inducer pretreatment were as described under Methods. Activity is expressed as nmol of product formed/time indicated. 
phenol with microsomes prepared from phenobarbital pretreated rats (6-min incubation) and the oxidation of bromobenzene via its 2,3-epoxide to o-bromophenol (5-min incubation) with microsomes prepared from $\beta$-naphthoflavone pretreated rats. Similar results were obtained with rats pretreated with 3-methylcholanthrene as was found with $\beta$-naphthoflavone. The enzymatic assay is sensitive enough to determine basal activity of bromobenzene epoxidation in noninduced rats. However, the formation of either $o$ - or $p$-bromophenol is markedly enhanced after pretreatment of the animals with various inducers. The noninduced activity for the formation of $p$-bromophenol was $74.3 \pm$ $14.9 \mathrm{nmol} / \mathrm{min} / 100 \mathrm{mg}$ of microsomal protein compared to $455.6 \pm 10.6 \mathrm{nmol}$ of $p$ bromophenol $/ \mathrm{min} / 100 \mathrm{mg}$ of microsomes prepared from phenobarbital-pretreated rats.
On the other hand the basal specific activity for $a$-bromophenol was $7.1 \pm 0.05 \mathrm{nmol} / \mathrm{min} /$ $100 \mathrm{mg}$ microsomal of protein compared to $64.4 \pm 16.7 \mathrm{nmol} / \mathrm{min} / 100 \mathrm{mg}$ of microsomes prepared from phenobarbital-pretreated rats. It was found that the production of either p-bromophenol via its 3,4-epoxide or 0 bromophenol via its 2,3-epoxide was dependent on the particular inducer employed. Figure 4 illustrates the gas chromatogram of $o-$ and $p$-bromophenol production from enzymatic epoxidation of bromobenzene with noninduced rat hepatic microsomes, microsomes prepared from pretreatment of rats with phenobarbital, 3-methylcholanthrene, or $\beta$-naphthoflavone. As can be observed phenobarbital induces both the $o$ - and the p-bromophenol pathway while 3-methylcholanthrene or $\beta$-naphthoflavone markedly induces only the $o$-bromophenol pathway.

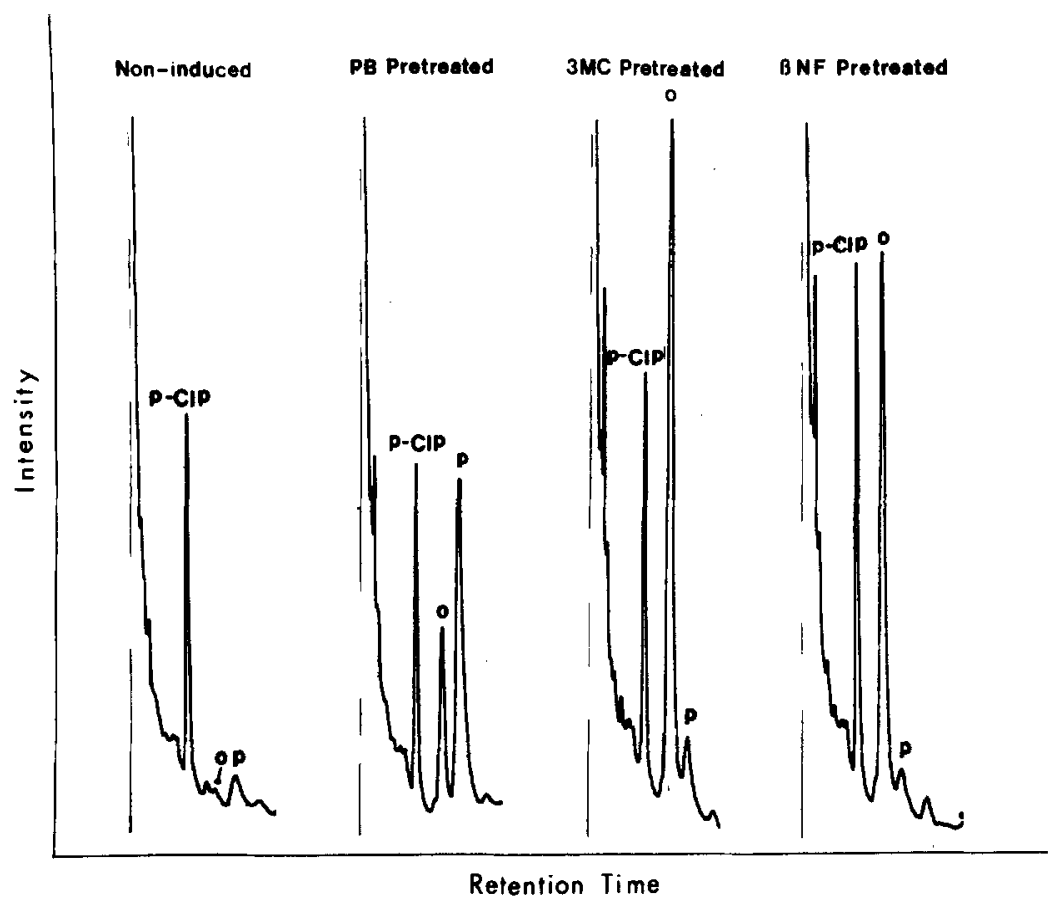

FIG. 4. Effect of the various inducers on the enzymatic formation of $o$ - and $p$-bromophenol. Three micromoles of bromobenzene was incubated with noninduced microsomes and microsomes prepared from rats pretreated with phenobarbital, 3-methylcholanthrene, or $\beta$-naphthoflavone as described under Methods. The gas chromatogram of acetyl derivatives of internal standard $p$-chlorophenol $(p \mathrm{Clp}), o$-bromophenol $(o)$, and $p$-bromophenol $(p)$ is shown in the figure. The extraction and derivatization of the products are described under Methods. 
With 3-methylcholanthrene. o-bromophenol production is $251.4 \pm 13.5 \mathrm{nmol} / \mathrm{min} / 100 \mu \mathrm{g}$ microsomal protein and with $\beta$-naphthoflavone, $169.7 \pm 36.7$ compared noninduced activity of $7.1 \pm 0.05$ (Table 1).

An investigation of these two pathways were undertaken to determine not only the effect of various inducers but more importantly to correlate the activity with various molecular forms of cytochrome $P-450$. Group of rats were treated with phenobarbital, 3-methylcholanthrene, or $\beta$-naphthoflavone

\section{TABLE 1}

ENZYMATIC CONYERSION OF BROMOBENZENE TO $o$-BROMOPHENOL AND $p$-BROMOPHENOL WITH LIVER MICROSOMES FROM RATS AND MICE

\begin{tabular}{lccc}
\hline & \multicolumn{2}{c}{ Specific activity } & \\
\cline { 2 - 3 } & $\begin{array}{c}o \text {-Bromo- } \\
\text { phenol }\end{array}$ & $\begin{array}{c}p \text {-Bromo- } \\
\text { phenol }\end{array}$ & $\begin{array}{c}o \text {-BP/ } \\
p \text {-BP }\end{array}$ \\
\hline Rats & & & \\
No Rx & & & \\
PB $^{d}$ & 7.1 & 74.3 & 0.10 \\
3MC & 64.4 & 455.6 & 0.14 \\
$\beta$ NF $^{f}$ & 251.4 & 60.1 & 4.18 \\
& 169.7 & 52.0 & 3.26 \\
Mice & & & \\
C3H/HeJ, No Rx & 35.8 & 35.8 & 1.00 \\
3MC & 105.5 & 47.8 & 2.21 \\
$\quad \beta$ NF & 133.5 & 47.5 & 2.81 \\
DBA/2J, No Rx & 60.0 & 45.6 & 1.32 \\
PB & 260.0 & 753.0 & 0.35 \\
3MC & 51.5 & 61.7 & 0.83 \\
$\beta$ NF & 42.0 & 66.2 & 0.63 \\
\hline
\end{tabular}

a Preparation of microsomes and enzymatic assay is as described under Methods. Three micromoles of bromobenzene was incubated. BP, bromophenol.

${ }^{b}$ Specific activity is $\mathrm{nmol}$ of product formed $/ \mathrm{min} /$ $100 \mathrm{mg}$ microsomal protein at $37^{\circ} \mathrm{C}$.

${ }^{c}$ Control animals received $0.2 \mathrm{ml}$ corn oil, ip; once a day for 5 days.

Animals were pretreated with phenobarbital, ip; once a day for 5 days $(50 \mathrm{mg} / \mathrm{kg})$.

${ }^{e}$ Animals were pretreated with 3-methylcholanthrene, ip; once a day for 5 days $(20 \mathrm{mg} / \mathrm{kg})$.

${ }^{f}$ Animals were pretreated with $\beta$-naphthoflavone, ip; once a day; in mice the dose was $40 \mathrm{mg} / \mathrm{kg}$ for 5 days; in rats the dose was increased to $60 \mathrm{mg} / \mathrm{kg}$ from days 3 to 5 . as described under Methods and equal quantities of microsomal protein were subjected to discontinuous polyacrylamide gel electrophoresis. The polypeptide pattern obtained with Coomassie blue staining consisted of multiple bands in the molecular weight region of 40,000 to 60,000 . As can be seen in Figure $5 \mathrm{~A}$, the band pattern was significantly altered with noninduced microsomes compared to the patterns obtained after induction with phenobarbital, 3-methylcholanthrene, or $\beta$-naphthoflavone. Both 3-methylcholanthrene and $\beta$-naphthoflavone which induced the formation of $o$-bromophenol increased the intensity of similar polypeptide bands with molecular weights of 50,000 and 54,000 . On the other hand, phenobarbital which induced the formation of $p$-bromophenol caused an increase of bands with molecular weights of 48,000 and 50,000 . In addition to the induction of particular cytochrome $P-450$ s, confirmation that this region contained heme was obtained with SDS treatment of microsomal preparations (in the absence of $\beta$-mercaptoethanol) and analyzed for heme with tetramethylbenzidine-hydrogen peroxide (Thomas et al., 1976; Moore et al. 1977). The heme staining bands were highly intensified in the 40,000 to 60,000 molecular weight region (Fig. 4B). Determination of the quantity of cytochrome $P-450$ in the various rat microsomal preparations indicated that phenobarbital pretreatment caused a threefold increase in the specific quantity of cytochorme P-450 compared to control microsomes $(1.58 \pm 0.25 \mathrm{~mole} / \mathrm{nmg}$ of microsomal protein compared to $0.53 \pm 0.04$ ). 3 -Methylcholanthrene and $\beta$-naphthoflavone caused a 2.4- and 2.2-fold increase, repectively (3-methylcholanthrene, $1.28 \pm$ $0.11 \mathrm{nmol} / \mathrm{mg}$ of microsomal protein; $\beta$ naphthoflavone, $1.20 \pm 0.11 \mathrm{nmol} / \mathrm{mg}$ of $\mathrm{mi}$ crosomal protein). These are average values from three experiments. These increases in the specific quantity of cytochrome $P-450$ with inducers correlated well with the increased intensity in the SDS-gel electrophoresis band patterns. These data are consistent with the 

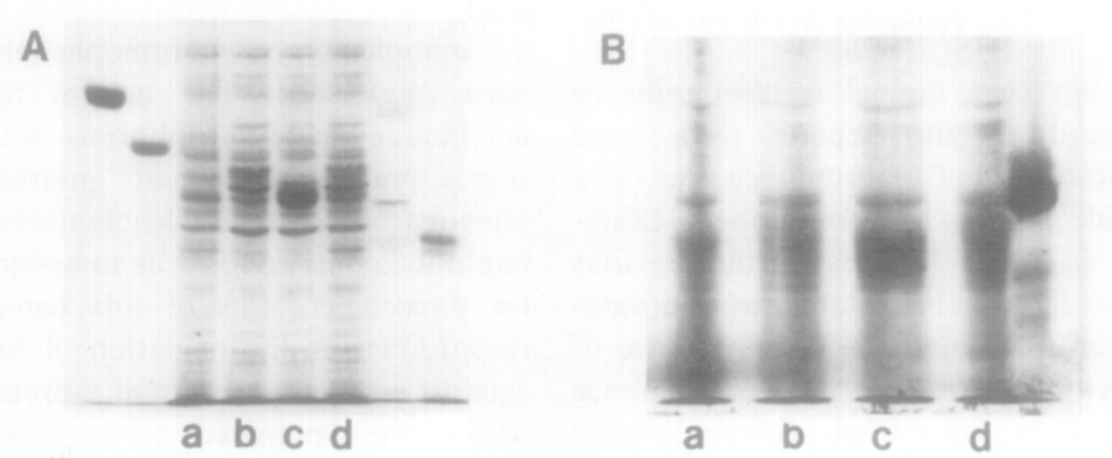

FIG. 5. SDS-Electrophoresis of rat liver microsomes after pretreatment with different inducers. (A) Electrophoresis was performed in a 0.75 -mm-thick $7.5 \%$ polyacrylamide gel as described under Methods. Each sample contained $5 \mu \mathrm{g}$ of protein; direction of migration was from top to bottom; the gel was stained with Coomassie blue. a, Untreated male albino Sprague-Dawley rat microsomes; b, rats, pretreated ip once a day with $\beta$-naphthoflavone $(40 \mathrm{mg} / \mathrm{kg}$ for 2 days followed by $60 \mathrm{mg} / \mathrm{kg}$ for 3 days); c, rats pretreated with phenobarbital ip once a day $(50 \mathrm{mg} / \mathrm{kg}$ for 5 days $)$; $\mathrm{d}$, rats pretreated with 3-methylcholanthrene, ip once a day $(20 \mathrm{mg} / \mathrm{kg}$ for 5 days $)$. The reference proteins are: bovine serum albumin, 68,000; catalase, 56,000; glucose-6-phosphate dehydrogenase, 51,000; horse radish peroxidase, 40,000. (B) SDS-Electrophoresis in the absence of mercaptoethanol was carried out in a 3-mm-thick $7.5 \%$ polyacrylamide gel; subsequent staining with tetramethylbenzidine- $\mathrm{H}_{2} \mathrm{O}_{2}$ was as described under Methods. Direction of migration was from top to bottom. Each sample contained $200 \mu \mathrm{g}$ of microsomal protein. a, Untrcated malc albino Spraguc-Dawlcy rat microsomes; $\mathrm{b}$, rats pretreated with $\beta$-naphthoflavone; c, rats pretreated with phenobarbital; d, rats pretreated with 3 -methylcholanthrene. The reference protein on the right is catalase with a molecular weight of 56,000 .

view that different forms of cytochrome $P-450$ catalyze $o$ - and $p$-hydroxylation of bromobenzene. However, conclusive evidence will rely on the isolation and purification of the specific forms.

Table 1 summarizes the specific activities of bromobenzene epoxidation to $o$-bromophenol and $p$-bromophenol in rats with and without pretreatment with various inducers In addition these activities were measured in two strains of mice, $\mathrm{C} 3 \mathrm{H} / \mathrm{HeJ}$ and the cytochrome $P$-448 noninducible 3-methylcholanthrene DBA/2J strain (Thorgeirsson and Nebert, 1977). As can be seen, the predominant pathway in non-induced rats is the formation of $p$-bromophenol (nine-fold greater than $o$-bromophenol). In contrast, the ratio of $p$-bromophenol to $o$-bromophenol in the two strains of mice were in the order of 1.0 , both genotypes of mice contained much more of the 2,3-epoxidation pathway to $o$-bromophenol compared to rats. In the rat, phenobarbital induces both $o$ - and $p$-bromophenol formation (ninefold for $o$-bromo- phenol and sixfold for $p$-bromophenol compared to noninduced microsomes). However, the activity of the 3,4-epoxide pathway to $p$-bromophenol is much higher than o-bromophenol. In the DBA/2J mice pretreated with phenobarbital, both pathways were also induced (fourfold for the $o$-bromophenol and 17-fold for $p$-bromophenol). 3-Methylcholanthrene and $\beta$-naphthoflavone which are relatively specific inducers for cytochrome $P-448$ were found to be highly selective for the induction of bromobenzene to o-bromophenol. No significant increase of $p$-bromophenol was found in the rat or in the mice. The increase of the specific activity of $o$ bromophenol formation in the rat was 35-fold with 3-methylcholanthrene and 24fold with $\beta$-naphthoflavone compared to noninduced microsomes. The $\mathrm{C} 3 \mathrm{H} / \mathrm{HeJ}$ had three- and four-fold increase with these inducers. In keeping with the noninducibility of DBA/2J strain, there was no effect on $o$-bromophenol production with either 3methylcholanthrene or $\beta$-naphthoflavone. 


\section{DISCUSSION}

There has been limited in vitro evidence with regard to the hepatic microsomal enzymatic oxidation of bromobenzene via a 2,3-epoxide pathway to o-bromophenol (Zampaglione et al., 1973). Most of the previous studies concerning the metabolism of bromobenzene utilized either the disappearance of ${ }^{14} \mathrm{C}$-labeled bromobenzene or the appearance of metabolites other than o-bromophenol (Mitchell et al., 1971; Reid et al., 1971a, b; Jollow et al., 1974).

These metabolites include $p$-bromophenol, bromocatechol, and bromophenyldihydrodiol. They were identified using thin-layer chromatography, liquid scintillation spectroscopy, reaction with Gibbs reagent, and mass spectroscopy (Jollow et al., 1974). We have developed an in vitro hepatic microsomal enzymatic assay of bromobenzene oxidation and the detection of $o$-bromophenol and $p$-bromophenol using gas chromatography with electron capture detection. The enzymatic assay utilized NADPH directly in place of a NADPH generating system thereby eliminating exogenous proteins which may compete for the covalent binding of reactive epoxides. The reaction rate for $o$-bromophenol and $p$-bromophenol formation is linear with time (for at least $6 \mathrm{~min}$ ) and proportional to enzyme concentration. The apparent Michaelis-Menten affinity constant $\left(K_{m}\right)$ for bromobenzene is $4 \times 10^{-4} \mathrm{M}$ with microsomes prepared from phenobarbital-treated rats. This value is in the same order of magnitude as was found by Zampaglione et al. (1973) with rat liver $9000 \mathrm{~g}$ supernatant fractions $\left(9.0 \pm 1.5 \times 10^{-4} \mathrm{M}\right)$. The detection of both $a$-bromophenol and $p$ bromophenol is highly reproducible and sensitive measuring as little as $0.2 \mathrm{ng}$ of the products per injection.

Although it is well established that phenobarbital, 3-methylcholanthrene, and $\beta$-naphthoflavone are inducers of various molecular forms of cytochrome $P-450$, the species of this heme protein responsible for the enzymatic conversion of bromobenzene to $o$-bromophenol or $p$-bromophenol has not been established. The use of SDS-polyacrylamide gel electrophoresis with microsomes prepared from rats pretreated with phenobarbital, 3-methylcholanthrene, or $\beta$ naphthoflavone enabled us to assign particular molecular forms of this heme protein responsible for the oxidation of bromobenzene to $o$-bromophenol and $p$-bromophenol. Microsomes prepared from 3-methylcholanthrene- or $\beta$-naphthoflavone-treated rats and subjected to SDS-polyacrylamide electrophoresis showed increases in Coomassie stain intensity for two polypeptide bands with molecular weights of 50,000 and 54,000. These molecular weights are within the 40,000 to 60,000 range established for this heme protein (Rikans et al., 1978; Ryan et al., 1975; Welton et al., 1975). Concomitant with this, both 3-methylcholanthrene or $\beta$-naphthoflavone caused a significant increase in the enzymatic formation of the $o$-bromophenol with no effect on the $p$ bromophenol pathway. In contrast, microsomes from phenobarbital treated rats showed a marked increase in polypeptide staining in the molecular weight region of 48,000 ; this increase in band intensity correlated well with the induction of the enzymatic formation of $p$-bromophenol. Phenobarbital, however, also caused some increase in the polypeptide band with a molecular weight of 50,000 ; a form induced by 3 -methylcholanthrene or $\beta$ naphthoflavone. This may explain, in part, the lack of specificity found with phenobarbital in that both the $p$-bromophenol and $o$-bromophenol pathways were inducible. Our in vitro evidence for the enzymatic conversion of bromobenzene to o-bromophenol coupled with the elucidation of specific forms of cytochrome $P-450$ induced by 3-methylcholanthrene or $\beta$-naphthoflavone is in keeping with the in rivo study of Zampaglione et al. (1973) who found that the major urinary metabolite in rats pretreated with 3-methylcholanthrene was $o$-bromophenol. It is interesting that bromobenzene undergoes two metabolic pathways, both of 
which are via epoxidation, however, each preferentially requiring different forms of cytochrome $P-450$; the phenobarbital inducible form leading to cellular damage while the 3-methylcholanthrene or $\beta$-naphthoflavone inducible form are not particularly detrimental. It will be of interest to resolve the biochemical reason for this since both of these epoxides are potentially reactive. In view of the fact that there is also a difference when one compares these pathways in mice, rats, and the established DBA/2J nonresponsive 3-methylcholanthrene mice, it is not unreasonable to propose that the variation in bromobenzene toxicity known to occur in various animals may in part by due to a genetic based predisposition for particular forms of the heme protein. This could lead to varying susceptibility to this environmental chemical. In addition, the effect of daily exposure to environmental inducers may cause induction of specific heme proteins which could alter the metabolic pathways of environmental contaminants such as bromobenzene. It will be of interest to correlate the extent of cytotoxicity due to bromobenzene with the administration of drugs which cause a phenobarbital type cytochrome $P-450$ induction or exposure to chemicals or drugs which cause 3-methylcholanthrene or $\beta$-naphthoflavone type cytochrome $P-450$ induction. Furthermore, the chemical covalent interaction of the reactive epoxide(s) with specific sites on tissue macromolecules warrants further investigation.

\section{ACKNOWLEDGMENTS}

This work was supported by a Barbour Scholarship at the University of Michigan, the University of Michigan Cancer Research Fund, and Grant 23007 from Hoffmann-LaRoche.

\section{REFERENCES}

Brodie, B. B., Reid, W. D., Cho, A. K., SiPes, G., Krishna, G., AND Gillette, J. R. (1971). Possible mechanism of liver necrosis caused by aromatic organic compounds. Proc. Nat. Acad. Sci. USA 68, 160-164.
Davis, D. C., Hashimoto, M., and Gillette, J. R. (1973). Effects of bromobenzene and carbon tetrachloride on the synthesis and release of proteins by perfused rat liver. Biochem. Pharmacol. 22, 1989-2001.

GilletTE, J. R. (1974). A perspective on the role of chemically reactive metabolites of forcign compounds in toxicity. Biochem. Pharmacol. 23, 2785-2794.

Jollow, D. J., Mitchell, J. R., Zampaglione, N., AND Gillette, J. R. (1974). Bromobenzeneinduced liver necrosis. Protective role of glutathione and evidence for 3,4-bromobenzene oxide as the hepatic metabolite. Pharmacology 11, 151-169.

Krishna, G., Eichelbaum, M., and Reid, W. D. (1971). Isolation and characterization of liver proteins containing covalently bound ${ }^{14} \mathrm{C}$-bromobenzene. Pharmacologist 13, 196.

LAEMMLI, U. K. (1970). Cleavage of structural proteins during the assembly of the head of bacteriophage T4. Nature (London) 227, 680-695.

Lowry, O. H., Rosebrough, N. J., FARR, A. L., AND RANDALL, R. J. (1951). Protein determination with the Folin phenol reagent. J. Biol. Chem. 193, 265-275.

Mitchell, J. R., Reid, W. D., Christie, B., MosKowitz, J., Krishna, G., AND Brodie, B. B. (1971). Bromobenzene-induced hepatic necrosis: Species difference and pretection by SKF 525-A. Res. Commun. Chem. Pathol. Pharmacol. 2, 877-888.

Moore, R. W., Welton, A. F., and Aust, S. D. (1977). Detection of hemoproteins in SDSpolyacrylamide gels. In Methods in Enzymology, Academic Press, New York, in press.

Omura, T., AND SATo, R. (1964). The carbon monoxide-binding pigment of liver microsomes. J. Biol. Chem. 239, 2370-2378.

ReID, W. D. (1972). Relationship between tissue necrosis and covalent binding of toxic metabolites of halogenated aromatic hydrocarbons. In Pharmacology and Future of Man, Proc. 5th Congr. Pharmacol., Vol. 2, pp. 62-74.

ReID, W. D. (1973). Mechanism of renal necrosis induced by bromobenzene or chlorobenzene. Exp. Mol. Pathol. 19, 197-214.

Reid, W. D., Cristie, B., Eichelbaum, M., and KRISHNA, G. (1971a). 3-Methylcholanthrene blocks hepatic necrosis induced by administration of bromobenzene or carbon tetrachloride. Exp. Mol. Pathol. 15, 363-372.

Reid, W. D., Cristie, B., Krishna, G., Mitchell, J. R. Moskowitz, J., AND Brodie, B. B. (1971b). Bromobenzene metabolism and hepatic necrosis. Pharmacology 6, 41-55.

Reid, W. D., Hett, K. F., Flick, J. M., AND Krishna, G. (1973). Metabolism and binding of aromatic hydrocarbons in the lung. Amer. Rev. Resp. Dis. 107, 539-551. 
ReID, W. D., AND KRISHNA, G. (1973). Centrolobular hepatic necrosis related to covalent binding of metabolites of halogenated aromatic hydrocarbons. Exp. Mol. Pathol. 18, 80-99.

RiKans, L. E., Smith, C. R., AND ZANNONI, V. G. (1978). Ascorbic acid and cytochrome P-450. $J$. Pharmacol. Exp. Ther. 204, 702-713.

Ryan, D., Lu, A. Y. H., Kawalek, J., West, S. B., AND Levin, W. (1975). Highly Purified cytochrome $P-448$ and $P-450$ from rat liver microsomes. Biochem. Biophys. Res. Commun. 64, 1134-1141.

Sipes, I. G., Gigon, P. and Krisna, G. (1971). Studies on the biliary excretion of bromobenzene metabolites. Pharmacologist 13, 196.

Sipes, I. G., Gigon, P. L., AND Krisna, G. (1974). Biliary excretion of metabolites of bromobenzene. Biochem. Pharmacol. 23, 451-455.

ThOMAS, P. E., Ryan, D., AND LeVIN, W. (1976).
An improved staining procedure for the detection of the peroxidase activity of cytochrome $P-450$ on sodium dodecyl sulfate polyacrylamide gels. Anal. Biochem. 75, 168176.

Thorgeirsson, S. S., and Nebert, D. W. (1977). The Ah locus and the metabolism of chemical carcinogens and other forcign compounds. $A d v$. Cancer Res. 25, 149-193.

Welton, A. F., O'Neal, F., Chaney, L. C., and AUST, S. D. (1975). Multiplicity of cytochrome $P-450$ haemoprotein in rat liver microsomes. Preparation and specificity of an antibody to the hemoprotein induced by phenobarbital. J. Biol. Chem. 250, 5631-5639.

Zampaglione, N., Jollow, D. J., Mitchell, J. R., Stripp, B., Hamrick, M., and Gillette, J. R. (1973). Role of detoxifying enzymes in bromobenzene-induced liver necrosis. J. Pharmacol. Exp. Ther. 187, 218-227. 